\title{
Packaging and shelf life of maize-peanut balls (Dakua)
}

\begin{abstract}
Maize-peanut balls (also known as dakua, dzowe or donkwa) is a street snack made from roasted, dried and milled maize and groundnuts/peanuts. It is often sold unpackaged by hawkers/vendors, in a portable food booth, food cart or food truck. However, the shelf life is unknown which makes this nutritious snack also a potential risk to consumers' health. In this study, the packaging and shelf life of maize-peanut balls (lab/self-made and those purchased from the local markets) were investigated by packaging in aluminum foil, flexible plastic films and unpackaged and stored at ambient temperature for 5 weeks. The products were analysed weekly for moisture, peroxide value, aflatoxin level, yeast and moulds during storage. Results indicate that the samples had variable moisture content, which decreased from the start of the analysis to the third week and increased again. Over the 5 weeks storage period, peroxide values increased to $\sim 0.4 \mathrm{mEq} / \mathrm{kg}$. The unpackaged samples had the highest aflatoxin level ( 21.74ppb), which is above the acceptable limit of $20 \mathrm{ppb}$. The samples packaged in flexible plastic film, however, had the lowest aflatoxin level $(\sim 13.15 \mathrm{ppb})$ whereas samples packaged in aluminum foil had values of $\sim 16.75 \mathrm{ppb}$. The estimated shelf life is approximately 8 weeks with flexible plastic films as the most suitable packaging material.
\end{abstract}

Keywords: dakua, dzowe, donkwa, groundnut-maize balls, shelf life, processing, packaging, HPLC, WHO
Volume 4 Issue $6-2017$

\section{Abena K Osae, Jacob K Agbenorhevi, Faustina DWireko Manu \\ Department of food science and technology, Kwame Nkrumah university of Science and Technology, Ghana}

Correspondence: Jacob K Agbenorhevi, Department of food science and technology, Kwame Nkrumah university of Science and Technology, Kumasi, Ghana, Tel +233208954223 Email jkagbenorhevi@yahoo.com, jkagbenorhevi.cos@knust. edu.gh

Received: July 20, 2016 | Published: August 15, 2017

\section{Introduction}

Maize-groundnut balls (also known as dakua in Akan and dzowe in Ewe) originated from Nigeria where it is known as donkwa and has been adopted by the Voltarians in Ghana. Dakua is a traditional food ${ }^{1}$ basically made from groundnuts ${ }^{2-3}$ maize and some spices (Figure 1). It is a street food, simply because it is a ready-to-eat food sold in the street or any public place such as the market by a hawker or vendor, normally in a portable food booth, food cart or food truck. ${ }^{4}$

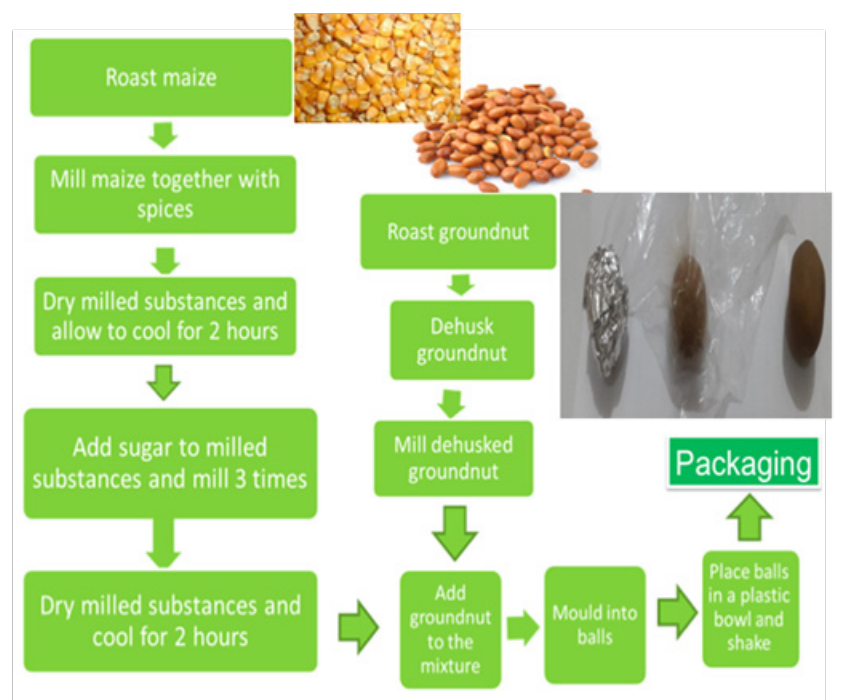

Figure I Processing of maize-peanut balls (Dakua).
Dakua is nutritious due to its maize and groundnut content. These constituents enrich the product and cause it to be highly nutritious. ${ }^{5}$ In Ghana, like other snack foods, dakua is mainly produced and consumed in its areas of production and production is based on art and skills rather than scientific knowledge. Production varies with people, culture and geographical locations: these leads to possession of variable characteristics. ${ }^{6}$ Some of the problems associated with the local production of snacks such as dakua include non-standardization of equipment, process and raw material, inadequate hygiene during and after production, and little or no packaging which results in poor preservation techniques and high levels of contaminants in the food resulting in food borne illnesses.

Dakua is a street snack consumed by many due to its nutritional value. However, a lot more people are concerned about the way dakua is handled after processing before it is sold to consumers. This also leads to high levels of contaminants in the food resulting in food borne illnesses. Due to this, many people do not patronize this snack in bulk because of the little knowledge of its shelf-life with respect to packaging. A well-developed storage plan for Dakua is one that will therefore be useful to both producers and consumers; where the glossy appearance, smooth texture, suitable peroxide value, aflatoxins and nutritional value is maintained over a longer period of time. The main objective of this study is to develop a suitable packaging for the dakua snack and also to evaluate the effects of these packages on shelf-life.

\section{Methodology}

\section{Materials and sample preparation}

Samples were obtained from 3 sources: Kwadaso area, Tech junction and those prepared in the food science kitchen, Forig, KNUST. Samples were stored at room temperature. Dakua (Sample 
C) was produced (according to the Flow chart as shown in Figure 1) using roasted Maize $(900 \mathrm{~g})$, roasted Groundnut $(900 \mathrm{~g})$, sugar $(600 \mathrm{~g})$, ginger $(250 \mathrm{~g})$, dried red pepper $(50 \mathrm{~g})$, Ethiopian pepper $(50 \mathrm{~g})$, nutmeg $(50 \mathrm{~g})$, gloves $(40 \mathrm{~g})$ and salt $(10 \mathrm{~g})$.

Products were also obtained from 2 different sources ( $\mathrm{A}=\mathrm{K}$ wadaso; $\mathrm{B}=$ Tek Junction)

Maize grains and groundnut were manually cleaned. They were then washed in tap water and $400 \mathrm{~g}$ each were soaked in 2 litres of water for 12 hours after which they were germinated for 72 hours. After germination, the maize and groundnut seeds were oven dried at $105^{\circ} \mathrm{C}$ for sixty minutes. The groundnut seeds were roasted at $140^{\circ} \mathrm{C}$ for thirty minutes while the maize was roasted at $140^{\circ} \mathrm{C}$ for sixty minutes. The groundnut was de-coated, after which both maize and groundnut were milled separately using a local attrition mill. After milling, the maize flour was sieved to obtain a particle size of $0.05 \mathrm{~mm}$. The maize flour and groundnut paste were then mixed together in a 1:1 ratio. To every $100 \mathrm{~g}$ of this mixture, $10 \%$ and $5 \%$ respectively of table sugar and powdered red pepper were added. The mixture was then passed through the attrition mill once and moulded into balls. The Dakua balls were then packaged in aluminum foil and flexible film while some were left unpackaged. The packaged and unpackaged samples were stored in a 'sieve' at ambient temperature. ${ }^{8}$ The products were analyzed for moisture, peroxide value, aflatoxin, yeast and moulds every week using standard procedures..$^{9-11}$ The shelf-life was estimated using Statsgraphics Centurion software (2008).

\section{Isolation and enumeration of yeasts and moulds}

Ten grams of the sample was weighed and homogenized with $90 \mathrm{~mL}$ of Saline Peptone Solution in a stomacher. Suitable serial dilutions were made. One $\mathrm{ml}$ was inoculated in Petri dishes. $15 \mathrm{~mL}$ of molten medium (cooled to $45 \pm 1^{\circ} \mathrm{C}$ ) was poured into the Petri dishes, mixed and allowed to set, incubated at $25^{\circ} \mathrm{C}$ for 3 days and then counted under a microscope with oil immersion objective lens. ${ }^{9}$

\section{Aflatoxin determination}

The aflatoxin content was determined by means of high performance liquid chromatography (HPLC). Fifty grams of ground sample were placed into ultraturrax and then $100 \mathrm{~mL}$ of $60 \%$ acetonitrile/water (v/v) added. The mixture was stirred for $2 \mathrm{~min}$ at high speed. The extract was filtered through a Whatman No.3 filter paper and then through a microfiber filter. Two milliliters $(2 \mathrm{~mL})$ of the final extract, corresponding to $1 \mathrm{~g}$ of the original material was diluted with $48 \mathrm{~mL}$ of phosphate buffered saline (PBS, pH 7.4, R-Biopharm Rhone) to give a solvent concentration of $2.5 \%$ or less (in order to protect the antibodies in immunoaffinity columns). The mixture was allowed to pass through column at a flow rate of $5 \mathrm{~mL} / \mathrm{min}$. The column contains monoclonal antibodies to aflatoxins bound to a solid support. By passing the diluted extract through column any aflatoxins present in the sample are bound to the antibody within the column. The column was then washed with $20 \mathrm{ml}$ of PBS. The elution of aflatoxins was done with $1.5 \mathrm{~mL}$ of methanol and $1.5 \mathrm{~mL}$ of pure water. $100 \mu \mathrm{L}$ of the samples were injected into the HPLC column heated to $40^{\circ} \mathrm{C}$. The mobile phase was water: methanol solution $(60: 40, \mathrm{v} / \mathrm{v})$. To $1 \mathrm{~L}$ of mobile phase were added $119 \mathrm{mg}$ of potassium bromide and $350 \mu \mathrm{L}$ of $4 \mathrm{M}$ nitric acid. The flow rate was $1 \mathrm{~mL} / \mathrm{min}$. For fluorescent detection of aflatoxin B1 \& B2, the excitation wavelength was $362 \mathrm{~nm}$ whereas the emission wavelength was $425 \mathrm{~nm} .{ }^{11}$

\section{Peroxide value}

The soxhlet method was used for the extraction of the peanut oil from the Dakua samples. The peroxide value determination was performed on the extracted oil by means of AOAC Official method. ${ }^{12}$

\section{Results and discussion}

\section{Enumeration of yeasts and moulds}

The quantitative analysis of yeasts and moulds were determined every week for 4weeks. According to the World Health Organisation (WHO), the accepted level of yeasts and moulds in nuts is $5 \times 10^{3} \mathrm{CFU} / \mathrm{g}$. An increase in yealts and mold growth was observed in all the samples of both packaged and unpackaged (Figure 2). For source A, the fresh samples recorded values of less than $10 \mathrm{CFU} / \mathrm{g}$. The unpackaged sample increased to $120 \mathrm{CFU} / \mathrm{g}$ during the $2^{\text {nd }}$ week, there was a sharp increase to $180 \mathrm{CFU} / \mathrm{g}$ and gradually to $210 \mathrm{CFU} / \mathrm{g}$ during the 4 th week. For the samples packaged in plastic, the increase was from an insignificant value of less than $10 \mathrm{CFU} / \mathrm{g}$ to $110 \mathrm{CFU} / \mathrm{g}$ and then $150 \mathrm{CFU} / \mathrm{g}$ in the $3^{\text {rd }}$ week and finally $190 \mathrm{CFU} / \mathrm{g}$ in the $4^{\text {th }}$ week. The samples packaged in aluminum foil recorded the lowest levels after every week. The samples had an initial microbial load of less than 10CFU/g which is insignificant and this increased to $100 \mathrm{CFU} / \mathrm{g}$ and then to $130 \mathrm{CFU} / \mathrm{g}$ and finally to $160 \mathrm{CFU} / \mathrm{g}$ after the $4^{\text {th }}$ week. For source B, there was also an initial microbial load of less than $10 \mathrm{CFU} / \mathrm{g}$ which increased over a period of 4weeks. For the unpackaged samples, the load increased from 0 to $190 \mathrm{CFU} / \mathrm{g}, 250 \mathrm{CFU} / \mathrm{g}$ and lastly $290 \mathrm{CFU} / \mathrm{g}$ after the $4^{\text {th }}$ week. The samples packaged in aluminum also recorded values from 0 to $120 \mathrm{CFU} / \mathrm{g}, 160 \mathrm{CFU} / \mathrm{g}$ and after the $4^{\text {th }} \mathrm{week}, 210 \mathrm{CFU} / \mathrm{g}$. The samples packaged in plastic also had the same trend, that is, from 0 to $140 \mathrm{CFU} / \mathrm{g}, 170 \mathrm{CFU} / \mathrm{g}$ and $220 \mathrm{CFU} / \mathrm{g}$ after the $4^{\text {th }}$ week. For sample $C$, initially, the yeasts and moulds load was insignificant and this increased after every analysis. After the $2^{\text {nd }}$ week, the unpackaged samples recorded a value of $200 \mathrm{CFU} / \mathrm{g}$ then increased to $210 \mathrm{CFU} / \mathrm{g}$ and finally to $275 \mathrm{CFU} / \mathrm{g}$ after 4 weeks. The sample packaged in aluminum foil also increased to $160 \mathrm{CFU} / \mathrm{g}, 175 \mathrm{CFU} / \mathrm{g}$ and finally, $240 \mathrm{CFU} / \mathrm{g}$ after the $4^{\text {th }}$ week. Finally, the samples packaged in plastic recorded $170 \mathrm{CFU} / \mathrm{g}$ after the $2^{\text {nd }}$ week, $192 \mathrm{CFU} / \mathrm{g}$ after the $3^{\text {rd }}$ week and after the $4^{\text {th }}$ week, $255 \mathrm{CFU} / \mathrm{g}$.

From the results, it was noticed that the samples which were not packaged had a higher microbial load as compared to the others. This is due to the exposure of the samples to the atmosphere thereby adding on to the aerobic microbial load which multiply faster as compared to the anaerobic microbes. The increasing microbial load in the packaged samples may be due to the presence of anaerobic microbes. These microbes are otherwise known as facultative microbes and do not require energy for their growth and activities. There was microbial growth in all the samples with very similar trend and this increased as the weeks went by. Both samples seemed to have favourable conditions for the growth of the fungi present, be it anaerobic or aerobic. The microbes produce toxins and these toxins accumulate may cause cancerous effect when consumed over a period of time.

\section{Aflatoxin levels}

The aflatoxin level was determined after the $3^{\text {rd }}$ week where an increase in the number of colonies of yeasts and moulds was vividly seen. Aflatoxins are produced by Aspergillus flavus and Aspergillus parasiticus, species of fungi. They are said to be carcinogenic substances which occur naturally in the peanut. 


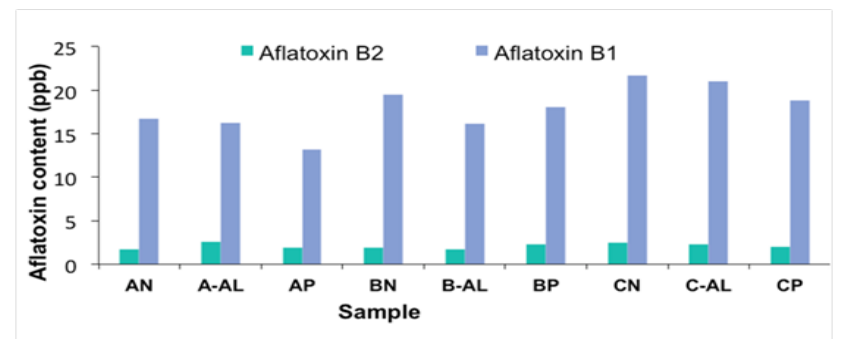

Figure 2 AN, source $A$ no packaging; $A-A L$, source $A$ aluminium packaging; $A P$, source $A$ plastic packaging; $B N$, source $B$, no packaging; $B-A L$, source $B$, aluminium packaging; $B$, source $B$, plastic packaging; $C N$, source $C$, no packaging; $\mathrm{C}-\mathrm{AL}$, source $\mathrm{C}$, aluminium packaging; $\mathrm{CP}$, source $\mathrm{C}$, plastic packaging.

The aflatoxins B1 and B2 were detected. Aflatoxin. ${ }^{13-14} \mathrm{~B} 1$ is the most toxic and frequently detected form. The level of aflatoxin increases as the colonies of these causative fungi also increase. From the results, it was noticed that the aflatoxin level at the $3^{\text {rd }}$ week was seen to be above the accepted WHO level which is $15 \mathrm{ppb}$. The levels were either slightly above or nearing the accepted Food and Drugs Authority, Ghana level, which is 20ppb (Figure 3). The highest level was recorded in the unpacked sample from source $\mathrm{C}$ which recorded a value of $21.74 \mathrm{ppb}$ followed by the source $\mathrm{C}$ sample packed in aluminum foil which read a value of $21.05 \mathrm{ppb}$. These values maybe be due to the handling of the raw peanut, from the farmer to the Dakua producer. The peanut, when handled improperly would encourage the growth of the aflatoxin producing fungi. It could also be due to the degree of processing done. This could be the peanut which may not have been processed enough to eliminate these toxins or better still kill the fungi which produce these toxins. The least levels recorded were from source A. The samples packed in plastic recorded the lowest level of $13.15 \mathrm{ppb}$. The samples packaged in aluminum foil recorded values of $16.75 \mathrm{ppb}$ and $16.28 \mathrm{ppb}$, respectively. This could also be related to the better handling of the raw material as compared to source $\mathrm{C}$ and also the degree of processing done to the raw materials.

\section{Moisture content}

Moisture content was recorded every week for samples from all 3 sources. The amount of moisture in the sample is important as it is a growth factor for microbes that might be present in a food sample. The amount of moisture would either support or hinder the growth of these microbes. Samples from Kwadaso had the highest initial moisture content recorded it had a value of $10.01 \%$. Samples from the food science kitchen recorded a value of $8 \%$ and samples from tech junction recorded a value of $7.03 \%$. The moisture content in all the samples followed the same trend. For the unpackaged samples, the moisture content decreased at a steady rate throughout the research. This was due to the loss of water into the atmosphere, in a form of water vapour, as a result of temperature change. The sample loses moisture to the atmosphere when the temperature of the sample is higher than that of the atmosphere. For the packaged samples, the moisture level was seen to have decrease to a point and after 3 weeks, it started to increase again. This was due to the fact that the samples were enclosed in a package, therefore when the sample loses moisture the moisture is trapped in the package. When the temperature reduces, the water vapour condenses and falls back on the sample, therefore adding on to the moisture content of the sample. The increase could also be attributed to the presence of anaerobic microbes. These are microbes which have the tendency to survive and indulge in their normal activities and functioning without the use of oxygen. These are the only microbes which would survive in a sample enclose in a tightly sealed package. These microbes produce alcohol and water and this water adds on to the moisture content of the sample. Basically, in the packaged samples, more moisture is present in the sample as these microbes increase and the temperature fluctuates whereas in the unpackaged samples, moisture is constantly lost. These microbes also produce alcohol and water as their by-products, the water also adds on to the quantity on water already available in the samples, thereby attributing to the increase of moisture after it has reduced or been used up by these microbes. ${ }^{7}$

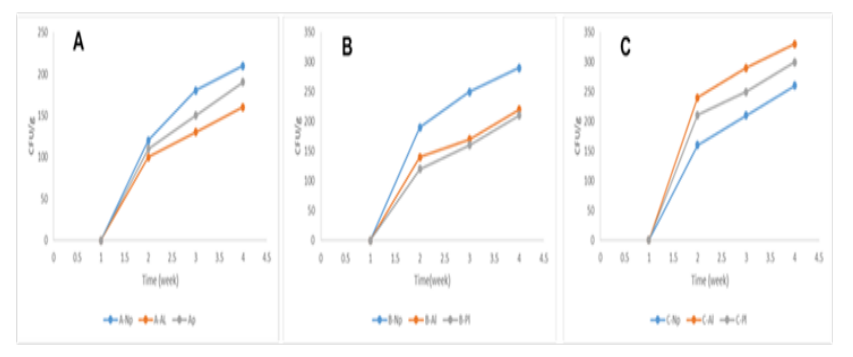

Figure 3 Yeasts and molds counts in Dakua samples from different sources (A, B, C).

\section{Peroxide value}

The peroxide value which is usually used as an indication of deterioration of oil measures the primary oxidative products (peroxides) of fat and oil. ${ }^{15}$ The peroxide values of the oil samples were relatively low. Over the 5weeks storage, peroxide values increased to $\sim 0.4 \mathrm{meq} / \mathrm{kg}$ (Figure 4 ). The low peroxide values of the samples are very stable and do not undergo rancidity at a fast rate and thus give an indication that peanut oil has a good storage potential. ${ }^{16,17}$

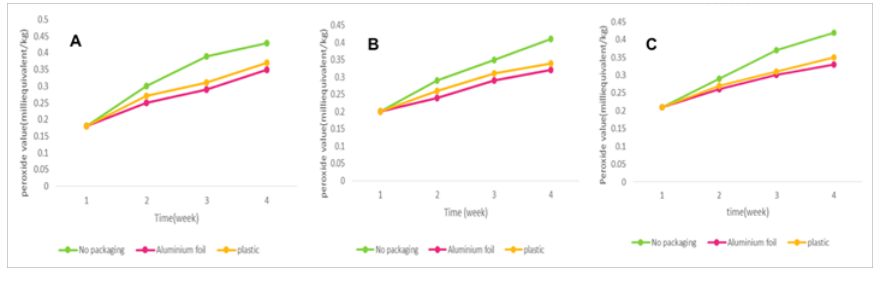

Figure 4 Peroxide values of Dakua samples $(A, B, C)$.

\section{Shelf life}

The shelf life was calculated using the Statsgraphics Centurion software (Stat Point, 2008). The results from the yeasts and moulds was used for the estimation shelf life.

The samples which were not packaged had lower shelf life compared to their corresponding packaged samples, except for source $\mathrm{C}$ (Table 1). This was due to the fact that the packaged source $\mathrm{C}$ samples recorded a higher microbial ${ }^{18}$ load as compared to the unpackaged ones. This could be attributed to the fact that the samples contained more facultative or anaerobic microbes and compared to the aerobic ones. It can also be traced to the raw materials or the environment in which the samples were produced. It was also noticed that the samples packaged in plastic had a lower shelf life as compared to those packaged in aluminum foil. ${ }^{19}$ Plastic is known to have 
micropores in the material so the product in the plastic can support the anaerobic microbes when there is not enough oxygen for their growth and activities and also the aerobic microbes when the material allows just enough oxygen into the packaged sample.

Table I Shelf life estimated for each sample

\begin{tabular}{ll}
\hline Sample & Shelf-life (week) \\
\hline A-NP & 9.83 \\
A-AL & 11.39 \\
A-PL & 10.62 \\
B-NP & 5.89 \\
B-AL & 8.57 \\
B-PL & 10.02 \\
C-NP & 8.87 \\
C-AL & 5.5 \\
C-PL & 5.78 \\
\hline
\end{tabular}

$A N$, source $A$ no packaging; $A-A L$, source $A$ aluminium packaging; $A P$, source $A$ plastic packaging; $B N$, source $B$, no packaging; $B-A L$, source $B$, aluminium packaging; $B P$, source $B$, plastic packaging; $C N$, source $C$, no packaging; $C-A L$, source $\mathrm{C}$, aluminium packaging; $\mathrm{CP}$, source $\mathrm{C}$, plastic packaging

From this study, it was noticed that the initial or raw materials used for the production of the product greatly affects the shelf life. Also, the conditions around the processing area also affects the shelf life. For instance, samples from source $\mathrm{C}$ were exposed to more anaerobic microbes and this affected the analysis done thereby causing the different direction in which the shelf life took. Therefore, Dakua can last for between 5 to 10 weeks depending on the packaging ${ }^{20,21}$ used.

\section{Conclusion}

The shelf life of Dakua was significantly influenced the nature of packaging. Dakua samples had variable moisture content during storage in the different packaging studied. The unpacked samples had the highest aflatoxin level ( 21.74ppb), which was above the acceptable limit of 20ppb (Food and Drugs Authority, Ghana). The samples packaged in flexible plastic film, however, had the lowest aflatoxin level $(\sim 13.15 \mathrm{ppb})$ whereas samples packaged in aluminum foil had values of $\sim 16.75 \mathrm{ppb}$. The estimated shelf life is approximately 8 weeks with flexible plastic films as the most suitable packaging material.

\section{Acknowledgements}

The authors are grateful to William Appaw of the Mycotoxin and Food Analysis Laboratories- KNUST for the technical support with the aflatoxin analysis.

\section{Conflicts of interest}

The author declares no conflicts of interest.

\section{References}

1. Aggarwal S, Beth D, Dunn C, et al. Eat Smart North Carolina: Snack and drinks. Raleigh, North carolins, USA: NC Division of Public health; 2007.

2. Ocheme B Ocheme, Ariahu C Chukwama, Ingbian E Kongo, et al
Prediction of shelf of Dakuwa (Nigerian Cereal/ groundnut snack) using $p H$ as an index of acceptability. Department of Food and Technology. Makurdi, Nigeria: University of Agriculture; 2014.

3. Otunola ET, Sunny Roberts EO, Adejuyitan JA, et al. Effects of addition of partially defatted groundnut paste on some properties of Kokoro (a popular snack made from maize paste). Department of Food Science and Engineering. Ogbomoso, Nigeria: Ladoke Atinkola University; 2015.

4. Artemis P Simopoulos, Ramesh Venkataramana Bhat. Street Foods. Switzerland: Karger Publishers; 2000.

5. Laryea D. Consumer perception of traditional foods and the nutritional composition of some selected traditional foods in Sekondi, in the Western region of Ghana. Dissertation presented to the department of Food Sience and Technology. 2012.

6. Ingbian EK, Akpapunam MA. Appraisal of tradition technologies in the processing and utilization of mumu, a cereal based local food product. African Journal of Food, Agriculture, Nutrition and Development; 2005. p. $1-18$.

7. Ocheme OB, Igyor MA, Hassan H. Isolation and characterization of microorganisms in dakuwa (a Nigerian cereal/groundnut snack). International Journal of Research in Pure and Applied Microbiology. 2014;4(1):15-19.

8. Laryea D. Consumer perception of traditional foods and the nutritional composition of some selected traditional foods in Sekondi, in the Western Region of Ghana. Dissertation presented to the department of Food Science and Technology. 2012.

9. Final Report and Executive Summaries from the AOAC international presidential task force on best practices in microbiological methodology AOAC International; 2006.

10. Nielsen SS. Food Analysis. Media, NY, USA: LLC; 2010.

11. AOAC Official Method. Fats (Total, Saturated, Unsaturated and Monosaturated) in cereal products. AOAC Official Method. 2005;996:01.

12. AOAC Official Method. Peroxide value of fats and oils. AOAC Official Method. 2006;965:33.

13. Leong YH, Ismail N, Latiff AA, et al. "Determination of aflatoxins in commercial nuts and nut products using liquid chromatography tandem mass spectrometry". World Mycotoxin Journal. 2011;4(2):119-127.

14. McDaniel A, Holmes WE, Williams P, et al. "Effect of Matrix CleanUp for Aflatoxin Analysis in Corn and Dried Distillers Grains". Natural Resources. 2011;2(4):250-257.

15. Chakrabart MM. Chemistry and technology of oils and fats chemistry and technology of oils and fats; 2008.

16. Hammond EG, Duvick D, Wang T, et al. Survey of the fatty acid composition of peanut (Arachis hypogaea) germplasm and characterization of their epoxy and eicosenoic acids. JAOCS. 1997;74(10):1235-1239.

17. Hashim IB, Koehler PE, Eitenmiller RR, et al. Fatty acid composition and tocopherol content of drought stressed florunner peanuts. Peanut Sci. 1993;20(1):21-24.

18. Moriartycraige S, Adkison J, Lynn M, et al. "Antioxidant supplements prevent oxidation of cysteine/cystine redox in patients with agerelated macular degeneration". American Journal of Ophthalmology. 2005;140(6):1020-1026.

19. Kowdley KV, Mason JB, Meydani SN, et al. "Vitamin E deficiency and impaired cellular immunity related to intestinal fat malabsorption. Gastroenterology. 1992;102(6):2139-2142. 
20. Glynn RJ, Ridker PM, Goldhaber SZ, et al. "Effects of random allocation to vitamin e supplementation on the occurrence of venous thromboembolism: report from the women's health study". Circulation. 2007;116(13):14971503 .
21. Gyesley SW. Total System Approach to predict shelf life of Packaged Food Products. In: Henyon DK editor. ASTM International in Food packaging Technology. 1991. p. 46-50. 